\title{
No Associations of Psychological Symptoms and Suicide Risk with Disaster Experiences in Junior High School Students 5 Years After the 20ll Great East Japan Earthquake and Tsunami
}

This article was published in the following Dove Press journal:

Neuropsychiatric Disease and Treatment

\author{
Kazuhiro Kawahara ${ }^{1,2}$ \\ Hirokage Ushijima (D) ${ }^{2}$ \\ Masahide Usami (iD ${ }^{2}$ \\ Minoru Takebayashi ${ }^{3}$ \\ 'Department of Neuropsychiatry, \\ Graduate School of Medical Science, \\ Kumamoto University, Kumamoto, Japan; \\ ${ }^{2}$ Department of Child and Adolescent \\ Psychiatry, Kohnodai Hospital, National \\ Center for Global Health and Medicine, \\ Chiba, Japan; ${ }^{3}$ Department of \\ Neuropsychiatry, Faculty of Life Sciences, \\ Kumamoto University, Kumamoto, Japan
}

Correspondence: Masahide Usami Email usami.masahide@hospk.ncgm.go.jp
Introduction: Natural disasters such as earthquakes can cause substantial damage and trauma, especially to children. The aim of this study was to examine the effects of disaster experience on psychological symptoms, suicide risk, and associated factors in junior high school students 5 years after the Great East Japan Earthquake (GEJE). The hypothesis of this study was that psychological symptoms and suicide risk of junior high school students are associated with disaster experience.

Methods: A cross-sectional survey consisting of questionnaires and face-to-face interviews with students at two junior high schools in Ishinomaki city, Miyagi Prefecture, Japan, about psychological symptoms, disaster situations, and their current environment 5 years after the GEJE was conducted. In total, data from 264 (117 boys [44.3\%] and 147 girls [55.7\%]) students were analyzed.

Results: There were no associations between disaster experience and PTSSC-15, DSRS-C, and SCAS scores. Those with evacuation experience and still living in temporary housing had significantly higher scores on the oppositional defiant behavior inventory (ODBI). Of these students, $29(11.0 \%)$ were considered to have suicide risk 5 years after the GEJE. The presence of depressive symptoms was the only factor related to suicide risk; no associations were found with sex, post-traumatic stress disorder (PTSD) symptoms, or other factors reported in previous studies, including disaster experience.

Conclusions: Disaster experience was not associated with psychological symptoms (PTSD, depression, anxiety) and suicide risk in junior high school students 5 years after the GEJE. The suicide risk appears to be the same as that in the general population in Japan. However, attention should be paid to externalization problems and depressive symptoms, an important suicide risk factor, even 5 years after the GEJE.

Keywords: disaster, Great East Japan Earthquake, long-term, psychological symptoms, suicide risk

\section{Introduction}

In the aftermath of natural disasters, a variety of social, political, economic, and health-related consequences can arise, including suicidal behaviors. ${ }^{1}$ Major mental health problems such as post-traumatic stress disorder (PTSD), depression, and suicidal behavior have been reported after a high-intensity earthquake. ${ }^{1-3}$ Psychological consequences after a disaster such as PTSD, depression, and anxiety 
appear to be common in the first months post-event, with a decrease over the first year or longer. ${ }^{4}$ However, some children after a disaster have a chronic trajectory, with $4 \%$ to $23 \%$ of children with PTSD symptoms and 2\% to $69 \%$ of children with depression symptoms one year later, which has been shown to be associated with disaster exposure, PTSD symptoms, female sex, negative coping, and lack of social support. ${ }^{5,6}$ The mental health of the parents, the quality of the parent-child relationship, and social support are considered to be very important to improve the recovery of children after a disaster. ${ }^{7}$ Psychological interventions are more likely to be effective during the short- and long-term recovery periods (1 month to several years post disaster), especially when used in combination with some form of screening for at-risk individuals. $^{4}$

Suicide prevention is one of the most important factors for the mental health of children after a disaster. Suicidal ideation has been found in $10.8 \%$ of children at 1 month $^{8}$ and in $16.8 \%$ of adolescents at 2 months after a disaster. ${ }^{9}$ An increased risk of suicide has also been found in $19.2 \%$ at 3 months after a disaster. ${ }^{10}$ Over the long term, suicidal ideation 3 years after a disaster was $11.3 \%,{ }^{11}$ and 6 years after it was $7.2 \% .{ }^{12}$ Looking at the changes over time, suicidal ideation has been seen in $35.6 \%, 33.2 \%$, and $30.7 \%$ of high school students 6,12 , and 18 months after an earthquake. ${ }^{13}$ Therefore, about $10-30 \%$ of children have been found to have suicidal ideation after a disaster, and increased suicide risk is still seen in some after many years. However, few surveys of suicide risk have been conducted using structured interviews of elementary and junior high school students a long time after a natural disaster.

The most relevant factors for increased suicidal behavior after disasters appear to be current major depression, PTSD, and previous mental health problems. ${ }^{1}$ Female sex, separation from the family, psychological abuse, and neglect have been also reported to be associated with suicide risk. ${ }^{13,14}$ However, reports of suicide risk and associated factors in children following a natural disaster have varied, and no definitive conclusions have been reached.

In addition, externalization problems and maladaptive behaviors can occur in adolescents after a traumatic event. ${ }^{15}$ Recent research has extended the examination of outcomes beyond internalizing conditions such as PTSD, anxiety, and depression to include externalizing conditions such as behavior problems, substance use, functional and cognitive impairments, traumatic grief, and post-traumatic growth. ${ }^{16}$

The Great East Japan Earthquake (GEJE), which involved a massive earthquake followed by a deadly tsunami, occurred on March 11, 2011. We previously collected information on activities of daily living, environmental damage, and traumatic symptoms among kindergarten, elementary, and junior high school student survivors 8,20 , and 30 months after the GEJE. ${ }^{17-23}$ Traumatic symptoms in elementary and junior high school students at 8 months depended on sex, age, and bereavement experience, in addition to environmental damage. ${ }^{19}$ Thirty months after the disaster, total PTSSC-15 scores and PTSD subscales for affected children in grades 1 to 9 decreased compared to 8 months, but they were not significantly different from 20 months later. The PTSSC- 15 depression subscale for affected children 30 months after the disaster decreased significantly at 20 and 30 months compared to 8 months, and it was also significantly decreased compared to 20 months. ${ }^{22}$ As described above, the symptoms of PTSD and depression have been found to improve over time, but the long-term psychological effects remain unclear. More specifically, it may be important to assess suicide risk, which is one of the most important factors in children's mental health.

Therefore, this study aimed to examine the effects of disaster experience on psychological symptoms and suicide risk in junior high school students 5 years after the GEJE. The hypothesis of this study was that psychological symptoms and suicide risk of junior high school students are associated with disaster experience.

\section{Materials and Methods}

\section{Study Design and Settings}

As of July 31, 2019, as a result of the GEJE, 3184 deaths, including many children, had been reported in Ishinomaki city, Miyagi Prefecture, and 417 people were still missing. ${ }^{24}$ About $90 \%$ of the deaths were a result of the tsunami. Those who survived this traumatic experience lost much, including their homes, friends, and family members, and many were forced to live in shelters. The number of evacuees has been reported to be as high as 50,758 , and as of January 11,2012 , there were reports of 33,093 collapsed homes and buildings, including partially destroyed homes, 7102 newly constructed temporary homes, and 5899 newly constructed private rental homes. ${ }^{24}$ Five years after the GEJE, although some 
structures had been removed, many evacuees were still living in temporary housing.

We have been working with school boards since the acute post-earthquake period to provide ongoing social support, including psychological education for children and teachers and support for individual high-risk children. $^{25}$ In this cross-sectional study, we conducted a survey of junior high school students about psychological symptoms, disaster situations, and their current environment 5 years after the GEJE. This survey was conducted as part of the school education program under the initiative of the Board of Education in Ishinomaki city. Two junior high schools were selected as target schools so that the Ishinomaki City Board of Education could generalize the distribution of the disaster situation to all of Ishinomaki city. After providing an explanation of the study to 514 junior high school students and their parents at these two schools, written, informed consent to participate was obtained from $330(64.2 \%)$ students and their parents. The consent procedure was approved by the ethics committee of the National Center for Global Health and Medicine (NCGM-G-001902-01).

First, a questionnaire survey of symptoms of PTSD, depression, and anxiety was conducted. Next, a child's oppositional defiant behavior questionnaire was administered to the parents. In addition, the presence of housing damage and evacuation experience were investigated to assess the participants' degree of disaster experience. Similarly, their current housing situation was examined. Next, child and adolescent psychiatrists conducted face-toface interviews with the participants using the Japanese version 2005 of the Mini International Neuropsychiatric Interview for Children and Adolescents (MINI-KID). ${ }^{26}$ These psychiatrists underwent assessment training via video to ensure reliability between raters. An allinterviewer conference was held immediately after the interview survey to avoid inter-rater bias.

\section{Assessments and Measures}

The 15-Item Post-Traumatic Stress Symptom Scale for Children (PTSSC-15)

The PTSSC-15 is a self-rating questionnaire of stress responses in children after a disaster. It consists of the 10item Post-Traumatic Stress Symptom Scale (PTSS-10), which was used as a screening tool after both the 1995 Great Hanshin Earthquake and the 2004 Indian Ocean Earthquake and Tsunami, ${ }^{27,28}$ and an additional five questions believed to reveal important psychosomatic characteristics after a disaster (flashbacks, appetite loss, somatic reactions such as headaches and abdominal pain, attention deficits, and anxiety). The PTSSC-15 was developed in Japan. ${ }^{29}$ Each questionnaire item is scored on a six-point Likert-type scale (from $0=$ "completely disagree" to $5=$ "completely agree"). A higher total score indicates more severe traumatic symptoms. The depression subscale consists of insomnia (Question 1), withdrawal (Question 5), appetite loss (Question 12), inattention (Question 13), and physical symptoms (Question 14). The PTSD subscale consists of irritability (Question 4), displeasure (Question6), emotional upset (Question 7), avoidance (Question 8), nervousness (Question 9), guilt (Question 10), flashbacks (Question11), and anxiety (Question 15).

\section{Depression Self-Rating Scale for Children (DSRS-C)} The DSRS-C is an 18-item self-rating scale used to evaluate depressive symptoms in children and adolescents. ${ }^{30}$ Murata et $\mathrm{al}^{31}{ }^{31}$ standardized the Japanese version of the DSRS-C. Respondents are asked to rate how frequently they experienced depressive symptoms during the most recent 1-week period on a three-point Likert-type scale (from $0=$ "never" to $2=$ "most of the time"). Higher scores indicate stronger depressive tendencies.

\section{The Spence Children's Anxiety Scale (SCAS)}

The Japanese version of the SCAS is a 38-item measure of anxiety symptoms in children and adolescents. ${ }^{32}$ The SCAS is composed of the following six subscales: "separation anxiety disorder", "social phobia", "obsessivecompulsive disorder", "panic attack and agoraphobia", "physical injury fear", and "generalized anxiety disorder". Each item is rated in terms of frequency on a four-point Likert-type scale (from $0=$ "never" to 3 = "always"), with higher scores indicating stronger anxiety tendencies.

\section{Oppositional Defiant Behavior Inventory (ODBI)}

The ODBI is composed of 41 questions covering the Diagnostic and Statistical Manual of Mental Disorders, fourth edition, text revision (DSM-IV-TR) criteria for attention deficit hyperactivity disorder (ADHD), oppositional defiant disorder (ODD), and conduct disorder (CD). Items are worded as closely as possible to the DSM-IV-TR using a rating scale format. Each item is rated on a fourpoint Likert-type scale (from $0=$ "not at all" to $3=$ "very much"). Respondents with ODBI scores $>20$ (the high ODBI subgroup) are considered to have ODD. The 
internal consistency, test-retest reliability, and concurrent and divergent validity of the ODBI have been confirmed. ${ }^{33}$

\section{MINI-KID}

The MINI-KID is a short structured diagnostic interview that was developed to screen for psychiatric disorders in children and adolescents. ${ }^{34}$ The MINI-KID is divided into a number of modules related to psychiatric disorders; these include "major depressive disorder", "suicidality", "panic disorder", "agoraphobia", "separation anxiety disorder", "social anxiety disorder", "generalized anxiety disorder", specific phobia, alcohol dependence, alcohol abuse, substance dependence (non-alcohol), substance abuse (nonalcohol), obsessive-compulsive disorder, PTSD, ADHD, ODD, and CD. Specific modules were chosen based on the most common disorders expected to be found in children and adolescents according to international studies. The Japanese version 2005 of the MINI-KID has been used in a previous study in Japan. ${ }^{11,35}$ With the MINIKID screening tool, suicide risk in children is assessed through interviews with a child psychiatrist or psychologist. ${ }^{34}$ The Japanese version 2005 of the MINIKID defines a person who answers positively to any of the following questions as a lifetime suicide risk: "Have you ever felt so bad that you wished you were dead? (1 point)", "Have you ever tried to hurt or injure yourself? (2 points)", or "Have you ever tried to kill yourself? (4 points)." Further, if the lifetime suicide risk was positive, the suicide risk for the past month was assessed with the following questions. In the past month, "Did you wish you were dead? (1 point)", "Did you want to hurt yourself? (2 points)", "Did you think about killing yourself (6 points)", "Did you have a plan to kill yourself? (10 points)", and "Did you try to kill yourself? (10 points)". In the Japanese version 2005 of the MINI-KID, a total score of 1 or more is defined as suicide risk, a total score of $1-8$ is defined as low risk, a score of $9-12$ is defined as medium risk, and a score of 13 or more is defined as high risk.

\section{Statistical Analysis}

A statistical analysis of whether the psychological symptom scale scores for the PTSSC-15, DSRS-C, SCAS, and ODBI were related to housing damage, evacuation experience, and living in temporary housing was performed using the $t$-test. Next, the percentage of junior high school students who were considered to have suicide risk was calculated based on the MINI-KID. The $t$-test and chisquared test were then used to investigate whether suicide risk was related to psychological symptoms, disaster experiences, and current environment. Furthermore, factors related to suicide risk on univariate analysis were analyzed by logistic regression analysis. $P$ values $<0.05$ were considered significant. All analyses were performed using SPSS (version 26.0 for Mac; SPSS, Chicago, IL, USA).

\section{Results}

\section{Descriptive Information}

After excluding 66 respondents because of missing data, 264 (117 boys [44.3\%] and 147 girls [55.7\%]; mean age \pm standard deviation $[\mathrm{SD}]: 13.32 \pm 0.953$ years $)$ students

Table I Demographic Characteristics of the Participants

\begin{tabular}{|c|c|c|c|}
\hline \multicolumn{2}{|l|}{ Category } & \multicolumn{2}{|l|}{$\begin{array}{l}\text { Total } \\
(n=264)\end{array}$} \\
\hline & & $\begin{array}{l}\text { Mean or } \\
n\end{array}$ & $\begin{array}{l}\text { SD or } \\
\%\end{array}$ \\
\hline Grade & $\begin{array}{l}\text { 7th } \\
8 \text { th } \\
9 \text { th }\end{array}$ & $\begin{array}{l}81 \\
83 \\
100\end{array}$ & $\begin{array}{l}30.7 \\
31.4 \\
37.9\end{array}$ \\
\hline Sex & $\begin{array}{l}\text { Male } \\
\text { Female }\end{array}$ & $\begin{array}{l}117 \\
147\end{array}$ & $\begin{array}{l}44.3 \\
55.7\end{array}$ \\
\hline PTSSC-I5 & $\begin{array}{l}\text { Total } \\
\text { Male } \\
\text { Female }\end{array}$ & $\begin{array}{l}19.49 \\
16.82 \\
21.61\end{array}$ & $\begin{array}{l}14.75 \\
13.06 \\
15.69\end{array}$ \\
\hline DSRS-C & $\begin{array}{l}\text { Total } \\
\text { Male } \\
\text { Female }\end{array}$ & $\begin{array}{l}8.69 \\
7.85 \\
9.37\end{array}$ & $\begin{array}{l}5.49 \\
4.82 \\
5.91\end{array}$ \\
\hline SACS & $\begin{array}{l}\text { Total } \\
\text { Male } \\
\text { Female }\end{array}$ & $\begin{array}{l}20.65 \\
16.78 \\
23.73\end{array}$ & $\begin{array}{l}19.52 \\
19.16 \\
19.32\end{array}$ \\
\hline ODBI & $\begin{array}{l}\text { Total } \\
\text { Male } \\
\text { Female }\end{array}$ & $\begin{array}{l}11.19 \\
11.79 \\
10.72\end{array}$ & $\begin{array}{l}9.58 \\
9.72 \\
9.47\end{array}$ \\
\hline Housing damage & $\begin{array}{l}\text { Severe } \\
\text { None or slight }\end{array}$ & $\begin{array}{l}163 \\
101\end{array}$ & $\begin{array}{l}61.7 \\
38.3\end{array}$ \\
\hline $\begin{array}{l}\text { Evacuation } \\
\text { experience }\end{array}$ & $\begin{array}{l}\text { Yes } \\
\text { No }\end{array}$ & $\begin{array}{l}110 \\
154\end{array}$ & $\begin{array}{l}41.7 \\
58.3\end{array}$ \\
\hline Current residence & $\begin{array}{l}\text { Temporary housing } \\
\text { Homeowner or } \\
\text { renter }\end{array}$ & $\begin{array}{l}10 \\
254\end{array}$ & $\begin{array}{l}3.8 \\
96.2\end{array}$ \\
\hline
\end{tabular}

Abbreviations: PTSSC-15, 15-item post-traumatic stress symptom scale for children; DSRS-C, depression self-rating scale for children; SCAS, spence children's anxiety scale; ODBI, oppositional defiant behavior inventory; SD, standard deviation. 
Table 2 PTSSC-I5, DSRS, SCAS, and ODBI Scores and Housing Damage

\begin{tabular}{|c|c|c|c|c|c|c|c|c|c|}
\hline & \multirow{3}{*}{ Sex } & \multicolumn{6}{|c|}{ Housing Damage } & \multirow{3}{*}{ Effect Size } & \multirow{3}{*}{$P$-value } \\
\hline & & \multicolumn{3}{|c|}{ Absent } & \multicolumn{3}{|c|}{ Present } & & \\
\hline & & Mean & SD & $\mathbf{n}$ & Mean & SD & $\mathbf{n}$ & & \\
\hline \multirow[t]{3}{*}{ PTSSC-15 } & Total & 19.03 & 13.58 & 101 & 19.77 & 15.47 & 163 & 0.05 & 0.683 \\
\hline & Male & 18.53 & $|2.3|$ & 43 & 15.82 & 13.46 & 74 & 0.21 & $0.28 I$ \\
\hline & Female & 19.40 & 14.55 & 58 & 23.06 & 16.31 & 89 & 0.23 & 0.168 \\
\hline \multirow[t]{3}{*}{ DSRS-C } & Total & 8.23 & 4.98 & 101 & 8.98 & 5.79 & 163 & 0.14 & 0.279 \\
\hline & Male & 7.49 & 5.02 & 43 & 8.05 & 4.72 & 74 & 0.12 & 0.542 \\
\hline & Female & 8.78 & 4.92 & 58 & 9.75 & 6.47 & 89 & 0.16 & 0.329 \\
\hline \multirow[t]{3}{*}{ SCAS } & Total & 19.56 & 18.17 & 101 & 21.33 & 20.34 & 163 & 0.09 & 0.477 \\
\hline & Male & 18.19 & 18.94 & 43 & 15.96 & 19.36 & 74 & 0.12 & 0.547 \\
\hline & Female & 20.59 & 17.68 & 58 & 25.79 & 20.15 & 89 & 0.27 & 0.111 \\
\hline \multirow[t]{3}{*}{ ODBI } & Total & 10.76 & 9.05 & 101 & 11.46 & 9.90 & 163 & 0.07 & 0.566 \\
\hline & Male & 11.79 & 10.13 & 43 & 11.78 & 9.54 & 74 & 0.00 & 0.997 \\
\hline & Female & 10.00 & 8.17 & 58 & 11.19 & 10.24 & 89 & 0.13 & 0.458 \\
\hline
\end{tabular}

Abbreviations: PTSSC-15, 15-item post-traumatic stress symptom scale for children; DSRS-C, depression self-rating scale for children; SCAS, spence children's anxiety scale; ODBI, oppositional defiant behavior inventory; SD, standard deviation.

were finally included in the analysis. Table 1 shows the participants' basic characteristics. The mean \pm SD scores on the PTSSC-15, DSRS-C, SCAS, and ODBI were $19.49 \pm 14.75,8.69 \pm 5.49,20.65 \pm 19.52$, and $11.19 \pm 9.58$, respectively. Overall, $163(61.7 \%)$ respondents suffered housing damage in which more than half of their home was destroyed, 110 (41.7\%) had evacuation experience, and $10(3.8 \%)$ were still living in temporary housing.
Relationships Between Psychological Symptom Rating Scale Scores (PTSSC-15, DSRS-C, SCAS, and ODBI), Disaster Experience, and Current Living Situation

Table 2 shows a comparison of PTSSC-15, DSRS-C, SCAS, and ODBI scores between the respondents with and without housing damage in which more than half of their home was destroyed. No significant differences were

Table 3 PTSSC-15, DSRS, SCAS, and ODBI Scores and Evacuation Experience

\begin{tabular}{|c|c|c|c|c|c|c|c|c|c|}
\hline & \multirow{3}{*}{ Sex } & \multicolumn{6}{|c|}{ Evacuation Experience } & \multirow{3}{*}{ Effect Size } & \multirow{3}{*}{$P$-value } \\
\hline & & \multicolumn{3}{|c|}{ Absent } & \multicolumn{3}{|c|}{ Present } & & \\
\hline & & Mean & SD & $\mathbf{n}$ & Mean & SD & $\mathbf{n}$ & & \\
\hline \multirow[t]{3}{*}{ PTSSC-15 } & Total & 19.14 & 14.62 & 154 & 19.97 & 14.99 & 110 & 0.06 & 0.653 \\
\hline & Male & 17.20 & 13.09 & 75 & 16.14 & 13.14 & 42 & 0.08 & 0.676 \\
\hline & Female & 20.99 & 15.80 & 79 & 22.34 & 15.65 & 68 & 0.09 & 0.604 \\
\hline \multirow[t]{3}{*}{ DSRS-C } & Total & 8.49 & 5.39 & 154 & 8.97 & 5.65 & 110 & 0.09 & 0.486 \\
\hline & Male & 7.80 & 4.90 & 75 & 7.93 & 4.72 & 42 & 0.03 & 0.891 \\
\hline & Female & 9.15 & 5.77 & 79 & 9.62 & 6.10 & 68 & 0.08 & 0.635 \\
\hline \multirow[t]{3}{*}{ SCAS } & Total & 19.62 & 19.08 & 154 & 22.10 & 20.12 & 110 & 0.13 & 0.309 \\
\hline & Male & 16.67 & 18.69 & 75 & 16.98 & 20.19 & 42 & 0.02 & 0.934 \\
\hline & Female & 22.42 & 19.14 & 79 & 25.26 & 19.56 & 68 & 0.15 & 0.375 \\
\hline \multirow[t]{3}{*}{ ODBI } & Total & 10.04 & 8.77 & 154 & $|2.8|$ & 10.43 & 110 & 0.29 & 0.020 \\
\hline & Male & 10.83 & 9.70 & 75 & 13.50 & 9.62 & 42 & 0.28 & 0.154 \\
\hline & Female & 9.29 & 7.77 & 79 & 12.38 & 10.95 & 68 & 0.33 & 0.054 \\
\hline
\end{tabular}

Abbreviations: PTSSC-15, 15-item post-traumatic stress symptom scale for children; DSRS-C, depression self-rating scale for children; SCAS, spence children's anxiety scale; ODBI, oppositional defiant behavior inventory; SD, standard deviation. 
Table 4 PTSSC-I5, DSRS, SCAS, and ODBI Scores and Living in Temporary Housing

\begin{tabular}{|c|c|c|c|c|c|c|c|c|c|}
\hline & \multirow{3}{*}{ Sex } & \multicolumn{6}{|c|}{ Living in Temporary Housing } & \multirow{3}{*}{ Effect Size } & \multirow{3}{*}{$P$-value } \\
\hline & & \multicolumn{3}{|c|}{ Absent } & \multicolumn{3}{|c|}{ Present } & & \\
\hline & & Mean & SD & $\mathbf{n}$ & Mean & SD & $\mathbf{n}$ & & \\
\hline \multirow[t]{3}{*}{ PTSSC-I5 } & Total & 19.58 & 14.86 & 254 & 17.20 & 12.02 & 10 & 0.16 & 0.618 \\
\hline & Male & 16.77 & 12.99 & 111 & 17.83 & 15.59 & 6 & 0.08 & 0.846 \\
\hline & Female & 21.76 & 15.87 & 143 & 16.25 & 5.12 & 4 & 0.35 & 0.116 \\
\hline \multirow[t]{3}{*}{ DSRS-C } & Total & 8.81 & 5.54 & 254 & 5.70 & 2.98 & 10 & 0.57 & 0.010 \\
\hline & Male & 7.95 & 4.86 & 111 & 5.83 & 3.66 & 6 & 0.44 & 0.295 \\
\hline & Female & 9.48 & 5.95 & 143 & 5.50 & 2.08 & 4 & 0.68 & 0.185 \\
\hline \multirow[t]{3}{*}{ SCAS } & Total & 20.88 & 19.74 & 254 & 14.80 & 11.94 & 10 & 0.31 & 0.154 \\
\hline & Male & 17.06 & 19.62 & 111 & 11.50 & 3.56 & 6 & 0.29 & 0.491 \\
\hline & Female & 23.85 & 19.39 & 143 & 19.75 & 18.77 & 4 & 0.21 & 0.677 \\
\hline \multirow[t]{3}{*}{ ODBI } & Total & 10.85 & 9.30 & 254 & 20.00 & 12.60 & 10 & 0.97 & 0.003 \\
\hline & Male & 11.43 & 9.38 & 111 & 18.33 & 14.25 & 6 & 0.72 & 0.090 \\
\hline & Female & 10.39 & 9.25 & 143 & 22.50 & 11.12 & 4 & 1.30 & 0.011 \\
\hline
\end{tabular}

Abbreviations: PTSSC-15, I5-item post-traumatic stress symptom scale for children; DSRS-C, depression self-rating scale for children; SCAS, spence children's anxiety scale; ODBI, oppositional defiant behavior inventory; SD, standard deviation.

found. Table 3 shows comparisons of PTSSC-15, DSRS$\mathrm{C}$, SCAS, and ODBI scores between the respondents with and without evacuation experience. Those with evacuation experience had significantly higher ODBI scores (effect size $=0.29 ; p=0.020$ ). Table 4 shows comparisons of PTSSC-15, DSRS-C, SCAS, and ODBI scores between the respondents still living and not living in temporary housing. DSRS-C scores were significantly lower (effect size $=0.57 ; p=0.010)$ and ODBI scores were significantly higher (effect size $=0.97 ; p=0.003$ ) in those still living in temporary housing. Particularly among female respondents, ODBI scores were significantly higher (effect size $=1.30 p=0.011)$. Figure 1 shows the trajectory of PTSSC-15 total score, PTSD subscale score, and Depression subscale score in the affected children 5 years after GEJE, compared to them of 1, 2, 3 years after in our previous study. ${ }^{22}$ PTSSC- 15 total scores and PTSD subscale scores were decreased, and depression subscale

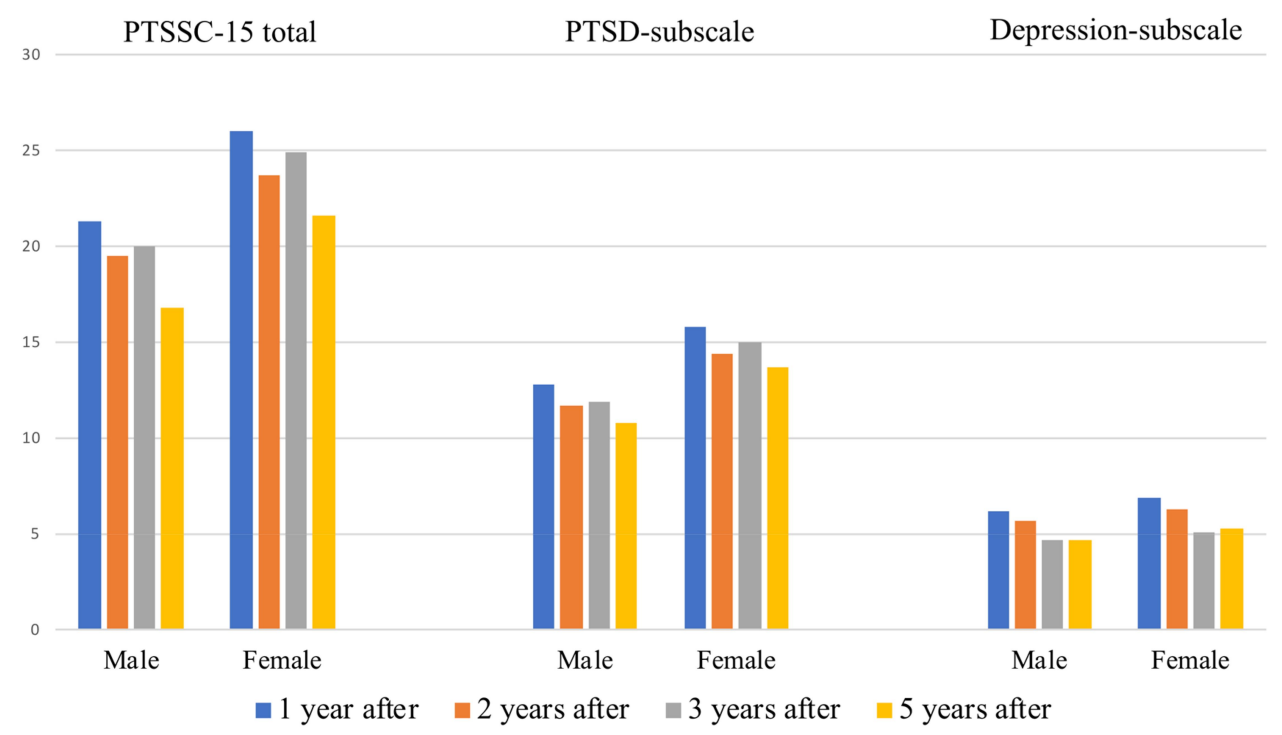

Figure I Trajectory of PTSSC-I5 total scores, PTSD subscale scores, and Depression subscale scores in surviving children 5 years after GEJE, compared to them of I, 2, 3 years after in our previous study. Notes: Reproduced from Usami M, Iwadare Y, Watanabe K et al Decrease in the traumatic symptoms observed in child survivors within three years of the 201 I Japan earthquake and tsunami. PLoS One. 2014;9: el 10898. Creative Commons license and disclaimer available from: http://creativecommons.org/ licenses/by/4.0/legalcode. 
Table 5 Breakdown of Suicide Risk in the Suicide Modules

\begin{tabular}{|c|c|c|}
\hline & $\mathbf{n}$ & $\%(n=264)$ \\
\hline \multicolumn{3}{|l|}{ Have you ever } \\
\hline Wished you were dead? & 21 & 8.0 \\
\hline Tried to hurt or to injure yourself? & 13 & 4.9 \\
\hline Tried to kill yourself? & 8 & 3.0 \\
\hline Any one or more of the above & 29 & 11.0 \\
\hline \multicolumn{3}{|l|}{ In the past month } \\
\hline Wished you were dead? & 6 & 2.8 \\
\hline Wanted to hurt yourself? & 4 & 1.5 \\
\hline Thought about killing yourself? & 4 & 1.5 \\
\hline Planned to kill yourself? & 3 & I.I \\
\hline Tried to kill yourself? & 1 & 0.3 \\
\hline Any one or more of the above & 9 & 3.4 \\
\hline \multicolumn{3}{|l|}{ Current suicide risk } \\
\hline Low (I-8 points) & 25 & 9.5 \\
\hline Moderate (9-12 points) & 0 & 0 \\
\hline High (>I3 points) & 4 & 1.5 \\
\hline
\end{tabular}

scores were maintained without an increase, although statistical comparisons are not possible due to the different samples.

\section{Prevalence of Suicide Risk and Factors Related to Suicide Risk}

Table 5 shows the number of junior high school students considered to have suicide risk based on the MINI-KID, and the corresponding number of each question item. In total, $29(11.0 \%)$ of the 264 junior high school students were considered to have suicide risk $(10.3 \%$ for boys and $11.6 \%$ for girls). Of these students, four (1.5\%) were considered to be at high risk and $25(9.5 \%)$ at low risk.

Table 6 shows the clinical features of junior high school students with and without suicide risk. Scores on the PTSSC-15 (effect size $=1.07 ; p<0.001$ ), DSRS (effect size $=1.22 ; p<0.001)$, and SCAS (effect size $=$ $0.73 ; p<0.001)$ were significantly higher in students with than in those without suicide risk. No significant associations were found with factors such as age, sex, housing damage, evacuation experience, and living in temporary housing. Table 7 shows the results of the logistic regression analysis taking confounding factors into account. Only the DSRS score showed a significant association with suicide risk (odds ratio [OR]: 1.16; 95\% confidence interval $[\mathrm{CI}]: 1.04-1.28 ; p=0.005)$. Analyses that excluded items regarding suicidal ideation obtained similar

Table 6 Prevalence of Suicide Risk in Surviving Children

\begin{tabular}{|c|c|c|c|c|c|c|c|}
\hline & & \multicolumn{2}{|c|}{$\begin{array}{l}\text { Suicide Risk } \\
\text { Yes }(n=29)\end{array}$} & \multicolumn{2}{|c|}{$\begin{array}{l}\text { Suicide Risk } \\
\text { No }(n=235)\end{array}$} & \multirow[b]{2}{*}{ Effect Size } & \multirow[b]{2}{*}{$P$-value } \\
\hline & & Mean or $n$ & SD or $\%$ & Mean or $n$ & SD or $\%$ & & \\
\hline Age, y & & 13.55 & 0.99 & 13.29 & 0.95 & 0.27 & $0.156^{\ddagger}$ \\
\hline Sex & $\begin{array}{l}\text { Male } \\
\text { Female }\end{array}$ & $\begin{array}{l}12 \\
17\end{array}$ & $\begin{array}{l}11.4 \\
13.1\end{array}$ & $\begin{array}{l}105 \\
130\end{array}$ & $\begin{array}{l}88.6 \\
86.9\end{array}$ & & $0.844 \dagger$ \\
\hline $\begin{array}{l}\text { PTSSC-I } 5 \\
\text { DSRS-C } \\
\text { SACS } \\
\text { ODBI }\end{array}$ & & $\begin{array}{l}32.80 \\
14.28 \\
33.10 \\
14.83\end{array}$ & $\begin{array}{l}14.12 \\
5.30 \\
20.11 \\
14.38\end{array}$ & $\begin{array}{l}17.85 \\
8.00 \\
19.11 \\
10.74\end{array}$ & $\begin{array}{l}14.00 \\
5.12 \\
18.93 \\
8.74\end{array}$ & $\begin{array}{l}1.07 \\
1.22 \\
0.73 \\
0.43\end{array}$ & $\begin{array}{l}<0.001^{\ddagger} \\
<0.001^{\ddagger} \\
<0.001^{\ddagger} \\
0.145^{\ddagger}\end{array}$ \\
\hline Housing damage & $\begin{array}{l}\text { Severe } \\
\text { None or slight }\end{array}$ & $\begin{array}{l}17 \\
12\end{array}$ & $\begin{array}{l}11.6 \\
13.5\end{array}$ & $\begin{array}{l}146 \\
89\end{array}$ & $\begin{array}{l}88.4 \\
86.5\end{array}$ & & $0.840 \dagger$ \\
\hline $\begin{array}{l}\text { Evacuation } \\
\text { experience }\end{array}$ & $\begin{array}{l}\text { Yes } \\
\text { No }\end{array}$ & $\begin{array}{l}14 \\
15\end{array}$ & $\begin{array}{l}14.6 \\
9.7\end{array}$ & $\begin{array}{l}96 \\
139\end{array}$ & $\begin{array}{l}85.5 \\
90.3\end{array}$ & & $0.550 \dagger$ \\
\hline Current residence & $\begin{array}{l}\text { Temporary housing } \\
\text { Homeowner } \\
\text { or renter }\end{array}$ & $\begin{array}{l}1 \\
28\end{array}$ & $\begin{array}{l}10.0 \\
11.0\end{array}$ & $\begin{array}{l}9 \\
226\end{array}$ & $\begin{array}{l}90.0 \\
89.0\end{array}$ & & $1.000 \dagger$ \\
\hline
\end{tabular}

Notes: ${ }^{\dagger}$ Comparisons between two groups by the chi-squared test. ${ }^{\ddagger}$ Comparisons between two groups by the unpaired $t$-test.

Abbreviations: PTSSC-15, 15-item post-traumatic stress symptom scale for children; DSRS-C, depression self-rating scale for children; SCAS, spence children's anxiety scale; ODBI, oppositional defiant behavior inventory; SD, standard deviation. 
Table 7 Factors Related to Suicide Risk in Surviving Children

\begin{tabular}{|l|l|l|l|}
\hline & OR & $\mathbf{9 5 \%} \mathbf{C l}$ & P-value \\
\hline PTSSC-15 & 1.04 & $0.99-1.09$ & 0.138 \\
DSRS-C & 1.16 & $1.04-1.28$ & 0.005 \\
SCAS & 0.99 & $0.96-1.02$ & 0.648 \\
\hline
\end{tabular}

Abbreviations: $\mathrm{Cl}$, confidence interval; OR, odds ratio; PTSSC-15, 15-item posttraumatic stress symptom scale for children; DSRS-C, depression self-rating scale for children; SCAS, spence children's anxiety scale.

results, with only DSRS scores significantly associated with suicide risk (OR: 1.14, 95\% CI: 1.03-1.27, $p=$ $0.015)$.

\section{Discussion}

\section{Relationships Between Psychological Symptoms, Suicide Risk, and Disaster Experience}

According to our study, ${ }^{22}$ significant improvements in PTSD and depressive symptoms in junior high school students were seen 20 and 30 months after compared to 8 months after the GEJE. Further, the present study suggests that PTSD symptoms might be recovered, and depression symptoms might be maintained without an increase compared to our previous study ${ }^{22}$ (Figure 1). Furthermore, no relationships were observed between PTSD symptoms, depression symptoms, and anxiety symptoms of junior high school students 5 years after the GEJE and housing damage or evacuation experience. As Tables 2 and 3 shows, it is very important to note that there were no associations between disaster experience and PTSD symptoms, depressive symptoms, and anxiety symptoms. There are several possible reasons. One is due to their resilience. Furthermore, a variety of social supports, including our activities, could have been effective in their recovery. It is also possible that multiple and complex factors were involved in the child's psychiatric symptoms over a long period of time and thus were not related to the disaster experience.

As for the ODBI scores, the questionnaire was parentcompleted, and it may not be appropriate to discuss them on a par with self-completed rating scales. In the present study, the results showed that children who had evacuation experience had significantly higher ODBI scores. This finding may suggest that the evacuation experience is a more sensitive reflection of the disaster experience than the extent of housing damage. Although the statistical power was low because of the small number of participants, and therefore difficult to assess, the findings of the present study also demonstrated that children who were still living in temporary housing had fewer depressive symptoms and more oppositional defiant symptoms. Overall, $3.8 \%$ of the children were still living in temporary housing five years after the disaster, and this is thought to be due to a variety of social factors, such as the parents' economic situation and mental state. In the present study, the results implied that depressive and oppositional defiant symptoms in children a long time after a disaster may be affected by the environment at the time of the disaster and thereafter, rather than the housing damage. Further longitudinal studies of oppositional defiant symptoms in children may be needed in the future.

On the other hand, the respective scores for a community sample of children of about the same age in Japan were $29.1 \pm 14.0$ for the PTSSC-15 score, ${ }^{29} 11.15$ \pm 6.79 for the DSRS-C score, ${ }^{36} 20.93 \pm 15.38$ for the SCAS score, ${ }^{32}$ and $13.5 \pm 10.1$ for the ODBI score. ${ }^{37}$ The findings of the present study do not seem to be much different from these. Therefore, the psychological symptoms of children in the affected areas may have subsided 5 years after the GEJE.

\section{Suicide Risk and Related Factors}

In the present study, 29 (11.0\%) junior high school students were considered to have suicide risk. And then, depressive symptoms were the only factor found to be related to suicide risk. No associations were found for sex, PTSD symptoms, and other factors that had been reported in previous studies as being related to suicide risk. There was no association with disaster experience, which refutes the hypothesis of this study.

A few studies have assessed suicide risk more than one year after a disaster. Eighteen months after the postFort McMurray wildfire, $16 \%$ of the students in grades 7 through 12 had suicidal ideation in the past month, compared to $4 \%$ of controls. ${ }^{38}$ Two years after the L'Aquila earthquake, the number of those between 17 and 18 years old responding positively to at least one suicidal screening item was $30(8.7 \%) .{ }^{15}$ In the Japanese research using MINI-KID of children 3 years after the GEJE aged 6-9 years, $11.3 \%$ of them had a suicide risk, particularly $18.5 \%$ of girls in the affected areas, compared to $4.5 \%$ of girls in non-affected areas, which was significantly higher. In the report by Tanaka, suicidal ideation was seen in $7.2 \%$, suicide plans in $2.0 \%$, and suicide attempts in $1.9 \%$ of adolescent survivors 6 years after the Wenchuan 
earthquake. ${ }^{12}$ Regional differences in suicide rates reflecting environmental and social risk factors are known to exist. ${ }^{39}$ Although these previous studies differ in type and severity of disaster, age, timing of survey, and assessment methods, the prevalence of suicide risk appears to be comparable to those of previous studies. However, in the present study, $8 \%$ of the students had suicidal ideation even once in the past, and $3.0 \%$ tried to kill themselves; this prevalence of suicide risk seemed somewhat high compared to those 6 years after the Wenchuan earthquake. $^{12}$ On the other hand, only six (2.8\%) junior high school students had had suicidal ideation in the past month, and nine (3.4\%) junior high school students met one of the items of suicidal ideation, self-harm ideation, suicidal plans, or suicidal attempts. Additionally, these findings in the past month are generally consistent with the rate of suicidal ideation in the control area. ${ }^{38}$

Furthermore, $17.2 \%$ of 14 to 18 -year-olds in a general community sample were found to have suicidal ideation, ${ }^{40}$ and the estimated lifetime prevalence of suicidal ideation in youths aged 13-17 years has been reported to be $12.1 \%,{ }^{41}$ similar to the findings of the present study. In a survey on suicidal ideation in children in Japan aged $7-15$ years, $414.8 \%$ of the responses to the statement "I don't think life is worth living" on the DSRS-C were "Mostly" and "Sometimes", respectively; this was nearly identical to the results of the present survey. ${ }^{36}$ Thus, it seems possible that this percentage of junior high school students with a suicide risk 5 years after the GEJE is about the same as that in the general population in Japan. Therefore, the suicide risk for children over the long term after the GEJE may have decreased.

It is important to note that predicting suicide risk is a complex challenge, and accurate prediction of low base rate events such as suicide is inherently difficult. There are many risk factors for suicide in adolescents (ie previous suicide attempt, psychiatric co-morbidity: mood, disruptive, and substance use disorders, dysfunctional personality traits, feelings of hopelessness and worthlessness, impulsive aggression, family history of depression or suicide, loss of a parent through death or divorce, family discord, physical and sexual abuse, lack of a support network, poor relationships with peers and feelings of social isolation, community or school environment, and having been exposed to suicide). ${ }^{42}$ In a long-term follow-up study after a disaster, the possibility that depressive symptoms were a more serious risk factor than PTSD symptoms for suicidal ideation was indicated in young survivors after an earthquake. ${ }^{13}$ According to the study of 6 years after the Wenchuan earthquake, suicidal ideation was significantly higher in children who experienced two or more traumatic experiences, with the loss of a family member or witnessing injury and/or death being a relevant factor, and house damage was not related. ${ }^{12}$ Compared to previous studies, in the present study, no associations were found for sex, PTSD symptoms, and other factors that had been reported in previous studies as being related to suicide risk. In a long-term 5 after the GEJE, the psychological effects of the disaster may have subsided, therefore there may not have been an association between these factors. However, the various factors such as traumatic experiences, abuse, and economic state were not sufficiently evaluated in the present study, so that this remains a topic for future research.

\section{Strengths and Limitations}

The strength of the present study is that the data regarding suicide risk after a natural disaster were collected through structured face-to-face interviews with children. The present study also had some limitations. First, the numbers of children considered to have suicide risk was small, and the statistical power was weak. Second, only a limited number of schools participated, and no psychiatric diagnoses were obtained. Third, this was a cross-sectional study and did not assess baseline psychological symptoms. Fourth, due to ethical issues and psychological effects, it was not possible to investigate factors such as family separation, the parents' mental health and economic situation, and abusive behaviors such as bullying. Fifth, suicide risk was assessed using the Japanese version 2005 of the MINI-KID, which is not standardized and is not the most current version, which may lead to discrepancies in the assessment. Sixth, the present study assessed only theoretical suicide risk and did not examine actual suicide attempts.

In the future, interventions and longitudinal research on mental health that consider the current living environment, such as the parents' economic situation and mental state, as well as the child's school life, will be required.

\section{Conclusions}

Disaster experience was not associated with psychological symptoms (PTSD, depression, anxiety) and suicide risk in junior high school students 5 years after the GEJE. The suicide risk appears to be the same as that in the general population in Japan. However, psychosocial care should 
continue to be provided to externalization problems and depressive symptoms, an important suicide risk factor, even 5 years after the GEJE.

\section{Ethical Approval}

This study was approved by the Certified Review Board of the National Center for Global Health and Medicine (NCGM-G-001902-01). Written, informed consent was obtained from the patients or their parents. All procedures involving human participants were conducted in accordance with the ethical standards of the Ethics Committee of the NCGM and with the 1964 Declaration of Helsinki and its later amendments, or comparable ethical standards.

\section{Acknowledgments}

The authors wish to express their deepest appreciation to the Ishinomaki City Educational Committee. The authors also wish to thank Kyota Watanabe, Masaki Kodaira, Yoko Muraoka, Yoshitaka Iwadare, Kumi Inazaki, Mihoko Kuroe, Yuki Hakoshima, Hiroaki Kihara, Remie Ogata, Keiko Kontani, Kanako Murakami, Hiroshi Hayakawa, Hirokazu Yoshida, Kyoko Yagishita, Maiko Harada, Akiko Takamatsu, Toyoshi Onishi, Kikue Maeda, Chiaki Katsumi, Yumiko Igarashi, Tetsuya Tanaka, Yoshinori Sasaki, Keisuke Sekine, Seiko Okamoto, Mako Morikawa, Ayumi Ishihara, Shuichi Suzuki, Naoko Sakamoto, Misa Uehara, Maiko Kamakura, Kazuya Mori, Yukiko Kizawa, Mari Shimizu, and Yoriko Hamada for cooperating with this survey, and Taeko Shiraishi, Takako Miyoshi, and Shuzo Ninomiya for creating and managing the database. The authors would also like to thank Asuka Koyama and Masateru Matsushita for their advice on the statistical analysis.

\section{Funding}

This study was supported by grants from the National Center for Global Health and Medicine (27-1403). This work was also supported in part by Grants-in-Aid for Research from the National Center for Global Health and Medicine (20A 3001). None of the funders was involved in the study design, the data collection and analysis, the decision to publish, or the preparation of the manuscript.

\section{Disclosure}

None of the authors has any commercial or financial involvements in connection with this study that represent or appear to represent any conflicts of interest.

\section{References}

1. Kolves K, Kolves KE, De Leo D. Natural disasters and suicidal behaviours: A systematic literature review. $J$ Affect Disord. 2013;146(1):1-14. doi:10.1016/j.jad.2012.07.037

2. Furr JM, Comer JS, Edmunds JM, Kendall PC. Disasters and youth: A meta-analytic examination of posttraumatic stress. $J$ Consult Clin Psychol. 2010;78(6):765-780. doi:10.1037/a0021482

3. Tang B, Liu X, Liu Y, Xue C, Zhang L. A meta-analysis of risk factors for depression in adults and children after natural disasters. BMC Public Health. 2014;14(1):623. doi:10.1186/1471-2458-14-623

4. Bonanno GA, Brewin CR, Kaniasty K, Greca AM. Weighing the costs of disaster: consequences, risks, and resilience in individuals, families, and communities. Psychol Sci Public Interest. 2010;11 (1):1-49. doi:10.1177/1529100610387086

5. Lai BS, Lewis R, Livings MS, La Greca AM, Esnard AM. Posttraumatic stress symptom trajectories among children after disaster exposure: a review. J Trauma Stress. 2017;30(6):571-582. doi: $10.1002 /$ jts. 22242

6. Lai BS, Auslander BA, Fitzpatrick SL, Podkowirow V. Disasters and depressive symptoms in children: a review. Child Youth Care Forum. 2014;43:489-504.

7. Pfefferbaum B, Jacobs AK, Houston JB, Griffin N. Children's disaster reactions: the influence of family and social factors. Curr Psychiatry Rep. 2015;17(7):57. doi:10.1007/s11920-015-0597-6

8. Lau JT, Yu X, Zhang J, et al. Psychological distress among adolescents in Chengdu, Sichuan at 1 month after the 2008 Sichuan earthquake. J Urban Health. 2010;87(3):504-523. doi:10.1007/ s11524-010-9447-3

9. Vehid HE, Alyanak B, Eksi A. Suicide ideation after the 1999 earthquake in Marmara, Turkey. Tohoku J Exp Med. 2006;208(1):19-24. doi:10.1620/tjem.208.19

10. Tang TC, Yen CF, Cheng CP, et al. Suicide risk and its correlate in adolescents who experienced typhoon-induced mudslides: a structural equation model. Depress Anxiety. 2010;27(12):1143-1148. doi: $10.1002 /$ da. 20748

11. Fujiwara T, Yagi J, Homma H, et al. Suicide risk among young children after the Great East Japan Earthquake: A follow-up study. Psychiatry Res. 2017;253:318-324. doi:10.1016/j. psychres.2017.04.018

12. Tanaka E, Tsutsumi A, Kawakami N, Kameoka S, Kato H, You Y. Long-term psychological consequences among adolescent survivors of the Wenchuan earthquake in China: A cross-sectional survey six years after the disaster. $J$ Affect Disord. 2016;204:255-261. doi:10.1016/j.jad.2016.08.001

13. Ran MS, Zhang Z, Fan M, et al. Risk factors of suicidal ideation among adolescents after Wenchuan earthquake in China. Asian J Psychiatr. 2015;13:66-71. doi:10.1016/j.ajp.2014.06.016

14. Tang W, Zhao J, Lu Y, et al. Suicidality, posttraumatic stress, and depressive reactions after earthquake and maltreatment: A cross-sectional survey of a random sample of 6132 chinese children and adolescents. J Affect Disord. 2018;232:363-369. doi:10.1016/j. jad.2018.02.081

15. Stratta P, Capanna C, Carmassi C, et al. The adolescent emotional coping after an earthquake: A risk factor for suicidal ideation. J Adolesc. 2014;37(5):605-611. doi:10.1016/j. adolescence.2014.03.015

16. Pfefferbaum B, Jacobs AK, Griffin N, Houston JB. Children's disaster reactions: the influence of exposure and personal characteristics. Curr Psychiatry Rep. 2015;17(7):56. doi:10.1007/s11920-015-0598-5

17. Iwadare Y, Usami M, Suzuki Y, et al. Posttraumatic symptoms in elementary and junior high school children after the 2011 Japan earthquake and tsunami: symptom severity and recovery vary by age and sex. J Pediatr. 2014;164(4):917-921. doi:10.1016/j. jpeds.2013.11.061 
18. Iwadare $\mathrm{Y}$, Usami M, Ushijima $\mathrm{H}$, et al. Changes in traumatic symptoms and sleep habits among junior high school students after the Great East Japan Earthquake and Tsunami. Sleep Biol Rhythms. 2014;12(1):53-61. doi:10.1111/sbr. 12047

19. Usami M, Iwadare Y, Kodaira M, et al. Relationships between traumatic symptoms and environmental damage conditions among children 8 months after the 2011 Japan earthquake and tsunami. PLoS One. 2012;7(11):e50721. doi:10.1371/journal.pone.0050721

20. Usami M, Iwadare Y, Kodaira M, et al. Sleep duration among children 8 months after the 2011 Japan earthquake and tsunami. PLoS One. 2013;8(5):e65398. doi:10.1371/journal.pone.0065398

21. Usami M, Iwadare Y, Watanabe K, et al. Prosocial behaviors during school activities among child survivors after the 2011 earthquake and Tsunami in Japan: a retrospective observational study. PLoS One. 2014;9(11):e113709. doi:10.1371/journal.pone.0113709

22. Usami M, Iwadare Y, Watanabe K, et al. Decrease in the traumatic symptoms observed in child survivors within three years of the 2011 Japan earthquake and tsunami. PLoS One. 2014;9(10):e110898. doi:10.1371/journal.pone.0110898

23. Usami M, Iwadare Y, Watanabe K, et al. Analysis of changes in traumatic symptoms and daily life activity of children affected by the 2011 Japan earthquake and tsunami over time. PLoS One. 2014;9(2): e88885. doi:10.1371/journal.pone.0088885

24. Ishinomaki city reconstruction policy department. Reconstruction from the Great East Japan Earthquake; 2019. Available from: https://www.city.ishinomaki.lg.jp/cont/10181000/8235/99hukkoujyou kyou_full.pdf. Accessed September 24, 2020.

25. Matsuda K, Usami M, Iwadare Y, Kodaira M, Watanabe K, Aoki M. Psychological care for children in lshinomaki after the earthquake and the tsunami. Japanese J Clin Psychiatry. 2012;41:1129-1135.

26. Otsubo T, Tanaka K, Koda R, et al. Reliability and validity of Japanese version of the mini-international neuropsychiatric interview. Psychiatry Clin Neurosci. 2005;59(5):517-526. doi:10.1111/j.1440-1819.2005.01408.x

27. Kato H, Asukai N, Miyake Y, Minakawa K, Nishiyama A. Posttraumatic symptoms among younger and elderly evacuees in the early stages following the 1995 Hanshin-Awaji earthquake in Japan. Acta Psychiatr Scand. 1996;93(6):477-481. doi:10.1111/j.16000447.1996.tb10680.x

28. Hafstad GS, Haavind H, Jensen TK. Parenting after a natural disaster: a qualitative study of norwegian families surviving the 2004 Tsunami in Southeast Asia. J Child Fam Stud. 2012;21(2):293-302. doi:10.1007/s10826-011-9474-Z

29. Tominaga Y, Takahashi S, Yosida R, Sumimoto K, Kajikawa N. Development and validity of a post-traumatic stress symptoms scale for Children (PTSSC-15)-child abuse and bulling- (In Japanese). J Hum Dev Clin Psychology. 2002;8:29-36.

30. Birleson P. The validity of depressive disorder in childhood and the development of a self-rating scale: a research report. J Child Psychol Psychiatry. 1981;22(1):73-88. doi:10.1111/j.1469-7610.1981. tb00533.x

Neuropsychiatric Disease and Treatment

\section{Publish your work in this journal}

Neuropsychiatric Disease and Treatment is an international, peerreviewed journal of clinical therapeutics and pharmacology focusing on concise rapid reporting of clinical or pre-clinical studies on a range of neuropsychiatric and neurological disorders. This journal is indexed on PubMed Central, the 'PsycINFO' database and CAS, and
31. Murata T, Shimizu A, Mori Y, Oushima S. Childhood depressive state in the school situation-consideration from the Birleson's Scale. Jpn J Psychiatr. 1996;1:131-138.

32. Ishikawa S, Sato H, Sasagawa S. Anxiety disorder symptoms in Japanese children and adolescents. J Anxiety Disord. 2009;23 (1):104-111. doi:10.1016/j.janxdis.2008.04.003

33. Harada Y, Saitoh K, Iida J, et al. The reliability and validity of the oppositional defiant behavior inventory. Eur Child Adolesc Psychiatry. 2004;13(3):185-190. doi:10.1007/s00787-004-0376-0

34. Sheehan DV, Sheehan KH, Shytle RD, et al. Reliability and validity of the mini international neuropsychiatric interview for children and adolescents (MINI-KID). J Clin Psychiatry. 2010;71(03):313-326. doi:10.4088/JCP.09m05305whi

35. Denda K. Diagnostic assessment of mood disorders in childhood and adolescence: using the MINI-KID structured diagnostic interview. J Child Adolesc Psychiatr. 2008;49:286-292.

36. Denda K, Kako Y, Kitagawa N, Koyama T. Assessment of depressive symptoms in Japanese school children and adolescents using the birleson depression self-rating scale. Int J Psychiatry Med. 2006;36 (2):231-241. doi:10.2190/3YCX-H0MT-49DK-C61Q

37. Sasaki Y, Usami M, Sasayama D, et al. Concerns expressed by parents of children with pervasive developmental disorders for different time periods of the day: a case-control study. PLoS One. 2015;10(4):e0124692. doi:10.1371/journal.pone.0124692

38. Brown MRG, Agyapong V, Greenshaw AJ, et al. After the Fort McMurray wildfire there are significant increases in mental health symptoms in grade 712 students compared to controls. BMC Psychiatry. 2019;19(1):18. doi:10.1186/s12888-018-2007-1

39. Thomas JTD, Yesim T, Andreas W Suicide and self-harming behavior. IACAPAP Textbook of Child and Adolescent Mental Health E.4; 2018. Available from: https://iacapap.org/content/ uploads/E.4-Suicide-update-2018.pdf. Accessed September 24, 2020.

40. Centers for Disease Control and Prevention. Youth Risk Behavior Surveillance System (YRBSS); 2017. Available from: https://www. cdc.gov/healthyyouth/data/yrbs/. Accessed September 24, 2020.

41. Nock MK, Green JG, Hwang I, et al. Prevalence, correlates, and treatment of lifetime suicidal behavior among adolescents: results from the national comorbidity survey replication adolescent supplement. JAMA Psychiatry. 2013;70(3):300-310. doi:10.1001/ 2013.jamapsychiatry.55

42. Dilillo D, Mauri S, Mantegazza C, Fabiano V, Mameli C, Zuccotti GV. Suicide in pediatrics: epidemiology, risk factors, warning signs and the role of the pediatrician in detecting them. Ital J Pediatr. 2015;41(1):49. doi:10.1186/s13052-015-0153-3 is the official journal of The International Neuropsychiatric Association (INA). The manuscript management system is completely online and includes a very quick and fair peer-review system, which is all easy to use. Visit http://www.dovepress.com/testimo-
nials.php to read real quotes from published authors.

\section{Dovepress}

